\title{
Conformational Analysis of Ethylene Oxide and Ethylene Imine Oligomers by Quantum Chemical Calculation
}

\author{
By Minoru KOBAYASHI,* and Hisaya SATO ${ }^{2}$
}

\begin{abstract}
Conformational analyses have been carried out for ethylene oxide (EO) and ethylene imine (EI) oligomer models (single chain) by quantum chemical calculations (RHF/6-31+G(d,p)). The conformations repeated for a unit of X-C, C-C and C-X bonds (X: $\mathrm{O}$ or $\mathrm{N}$ ) were examined. For optimizations of the EI oligomers, some designation systems with trans values were used, taking account of pseudoasymmetry. For the $\mathrm{EO}$ oligomers $\left(\mathrm{EO}-\mathrm{x}, \mathrm{x}=2\right.$ - to 8-mers), $(\mathrm{ttt})_{\mathrm{x}} \operatorname{and}\left(\mathrm{tg}^{+} \mathrm{t}\right)_{\mathrm{x}} \operatorname{conformers}$ were first and second stable $(\Delta \mathrm{E}=1.17-1.26 \mathrm{kcal} / \mathrm{m} . \mathrm{u}$.), respectively. On the contrary, for the EI oligomers (EI-x, $\mathrm{x}=2-$ to $11-$ mers), $\left(\operatorname{tg}^{+} t\right)_{\mathrm{x}}$ and $(\mathrm{ttt})_{\mathrm{x}}$ were first and second stable $(\Delta \mathrm{E}=1.32-1.42 \mathrm{kcal} / \mathrm{m} . \mathrm{u}$.$) , respectively. Therefore, the gauche$ preference of $\mathrm{C}-\mathrm{C}$ bond in EI-x is stronger than that in EO-x. The calculated structures of $(\mathrm{ttt})_{\mathrm{x}}$ and $\left(\operatorname{tg}^{+} \mathrm{t}\right)_{\mathrm{x}}$ in EO-x agreed with those observed by XRD analysis for PEO crystals in stretched (planar zigzag) and original (7/2 helix) states, respectively. The calculated structures of $\left(\operatorname{tg}^{+} t\right)_{\mathrm{x}}$ and $(\mathrm{ttt})_{\mathrm{x}}$ in EI-x also agreed with those observed for PEI crystals in dehydrate (7/2 helix) and hydrate (planar zigzag) states, respectively. However, the dihedral angles (EO-8) and the $5 \mathrm{~mol}$ length (EI-11) in both helices did not agree with each of the observed values for the polymers. Each difference between the oligomers (single chain) and polymers was estimated by the effect of intermolecular interactions in PEO or PEI. For $\left(\operatorname{tg}^{+} \mathrm{t}\right)_{\mathrm{x}}$ of EI-11, the existence of metastable skewed helical structures (reversed and/or kinked) were estimated in addition to the helix.

KEY WORDS: Conformation / Poly(ethylene oxide) / Poly(ethylene imine) / Oligomer / Quantum Chemical Calculation / Polymer

Crystal /
\end{abstract}

Poly(ethylene oxide) (PEO) and poly(ethylene imine) (PEI) have a commonality in that both have an electron-releasing heteroatom $(\mathrm{O}$ or $\mathrm{N})$ in the main chain of each molecule. However, the crystal structures of these polymers are different from each other. It has been made apparent from X-ray diffraction (XRD) analyses ${ }^{1,2}$ that the structure of PEO crystal in its original state is a $7 / 2$ helix, with the tgt ( $\mathrm{t}$ : trans, $\mathrm{g}$ : gauche) conformation repeated for O-C, C-C and C-O bonds, and it changes to a planar zigzag (ttt) conformation in the stretched state. XRD and other analyses ${ }^{3-6}$ have confirmed that the structure of the linear dehydrated PEI crystal is a 5/1 double stranded helix with the tgt conformation repeated for $\mathrm{HN}-\mathrm{C}, \mathrm{C}-\mathrm{C}$ and $\mathrm{C}-\mathrm{NH}$ bonds, and it changes to a planar zigzag (ttt) conformation in the hydrated state. In this manner, the conformations of both crystals in the original state are tgt (gauche preference of the $\mathrm{C}-\mathrm{C}$ bond); however, the structures (e.g. double stranded helix in PEI) and transformational behavior are considerably different. These differences may be connected with intra- and/or intermolecular interactions, although the details of factors dominating the formation of such crystal structures are complicated and have yet to be clarified. Applications exploiting the conformational and structural characteristics of these polymers have resulted in advances of a solid polymer electrolyte, ${ }^{7}$ a gene delivery polymer (PEI), ${ }^{8}$ and so on. Conformational analyses of these polymers based on various aspects are important for the molecular design of polymers for various applications.
For the conformational analyses of PEO and PEI, computational chemistry has been utilized to complement experimental observations. Mark et al. ${ }^{9,10}$ have reported pioneering works of PEO using the rotational isomeric state model (RIS). More recently, studies of $\mathrm{PEO}^{11,12}$ and $\mathrm{PEI},{ }^{12,13}$ using molecular mechanics (MM) and molecular dynamics (MD), have been reported. Meanwhile, studies using quantum chemical calculations, which differ from RIS, MM and MD in that the experimentally obtained force field constants are not used, have been reported. ${ }^{14-20}$ It is considered that this method is in a position to obtain accurate information of a single chain eliminating intermolecular interactions. Regarding PEO, Tsuzuki et al., ${ }^{14}$ Smith et al. ${ }^{15,16}$ and Sasanuma et al. ${ }^{17}$ reported results using a monomer (dimethoxyethane) as a model of PEO. Sasanuma et al. ${ }^{17,18}$ reported those using a trimer and pentamer. For PEI, Boesch et al. ${ }^{19}$ and Sasanuma et $a .^{20}$ reported results using the $N, N^{\prime}$-dimethylethylenediamine monomer as a model of PEI. However, no reports of conformational analyses and structural examinations using the larger molecular weight oligomer models for either polymer have been found.

In this study, a systematic conformational analyses for EO and EI oligomers having various molecular weight (1- to 11mers) has been carried out by quantum chemical calculations, in order to compare the basic conformational characteristics of both polymers. Recently, the authors ${ }^{21}$ reported on the conformational analysis of isotactic methylmethacrylate oligo-

\footnotetext{
${ }^{1}$ Graduate School of Bio-Applications and Systems Engineering, Tokyo University of Agriculture and Technology, Naka-cho, Koganei 184-8588, Japan ${ }^{2}$ Graduate School of Technical Management, Tokyo University of Agriculture and Technology, Naka-cho, Koganei 184-8588, Japan

*To whom correspondence should be addressed (Tel: +81-72-689-1918, Fax: +81-72-689-1918, E-mail: mikoba3@aol.com).
} 
mers (3- to 11-mers) by quantum chemical calculation, and the calculated results agreed with the observed results and supported the polymer structure with a 10/1 helix. Therefore, the same practice was attempted in this study. The energy priority of the conformers, the optimized structures, and the dependency of these features on the number of monomer units were examined. Through a comparison of calculated and observed results, the relations of these features with the polymer structures are discussed.

\section{QUANTUM CHEMICAL CALCULATIONS}

\section{Oligomer Models}

For the oligomer models (single chain) of PEO, EO x-mers ( $\mathrm{x}=1-8, \mathrm{x}$ : monomer unit number) capped by methoxy and methyl groups were used. For those of PEI, EI $x$-mers (x = 1-11) capped by $N$-methylimino and methyl groups were used. The specified models are given in Table I and Figure 1. As the conformational models of each oligomer, the following conformations: $\left(\tau_{\mathrm{n}} \tau_{\mathrm{n}+1} \tau_{\mathrm{n}+2}\right)_{\mathrm{x}}$ were designated: $(\mathrm{ttt})_{\mathrm{x}},\left(\mathrm{ttg}^{+}\right)_{\mathrm{x}}$, $\left(\operatorname{tg}^{+} \mathrm{t}\right)_{\mathrm{x}},\left(\operatorname{tg}^{+} \mathrm{g}^{+}\right)_{\mathrm{x}},\left(\operatorname{tg}^{+} \mathrm{g}^{-}\right)_{\mathrm{x}}$ and $\left(\mathrm{g}^{+} \mathrm{g}^{+} \mathrm{g}^{+}\right)_{\mathrm{x}}$ (t: trans; $\mathrm{g}^{+}, \mathrm{g}^{-}$: gauche) as the combinations of dihedral angles $(\tau)$ repeated for the unit of $\mathrm{X}-\mathrm{C}, \mathrm{C}-\mathrm{C}$ and $\mathrm{C}-\mathrm{X}$ bonds $(\mathrm{X}$ : $\mathrm{O}$ or $\mathrm{N}$, refer to Figure 1). All the dihedral angles were independently designated along the skeletal chains. For the trans and gauche values, $180^{\circ}(\pi)$ and $+60^{\circ}\left(\mathrm{g}^{+}\right)$or $-60^{\circ}\left(\mathrm{g}^{-}\right)$, were used for the EO and EI oligomers, respectively. In EI oligomer, each conformational energy optimized using the trans values of $\pi$ or an unidirectional angle $\left(150^{\circ}-175^{\circ}\right.$, or $\left.-150^{\circ}--175^{\circ}\right)$ was different, and the energies optimized using any unidirectional angles were same. Such effects have been also found in the conformational analyses of isotactic methylmethacrylate oligomers $^{21}$ mentioned above. Then, for the trans values of EI oligomers, $-175^{\circ}$ was used in addition to $\pi$.

\section{Conformational Analyses}

Conformational analyses were carried out for each model using quantum chemical calculations. The Gaussian $03 \mathrm{~W}$ (Gaussian Inc.) ${ }^{22}$ program was used. For structural optimizations, the restricted Hartree-Fock (RHF) method and density

Table I. Molecular models

\begin{tabular}{cclr}
\hline No. & $\begin{array}{c}\text { Monomer unit } \\
\text { number: } x\end{array}$ & \multicolumn{1}{c}{ Molecular models } & Molecular weights \\
\hline EO-1 & 1 & $\mathrm{CH}_{3} \mathrm{O}-\left(\mathrm{CH}_{2} \mathrm{CH}_{2} \mathrm{O}\right)_{1}-\mathrm{CH}_{3}{ }^{\mathrm{a}}$ & 90.14 \\
EO-2 & 2 & $\mathrm{CH}_{3} \mathrm{O}-\left(\mathrm{CH}_{2} \mathrm{CH}_{2} \mathrm{O}\right)_{2}-\mathrm{CH}_{3}$ & 134.20 \\
EO-3 & 3 & $\mathrm{CH}_{3} \mathrm{O}-\left(\mathrm{CH}_{2} \mathrm{CH}_{2} \mathrm{O}\right)_{3}-\mathrm{CH}_{3}$ & 178.26 \\
EO-5 & 5 & $\mathrm{CH}_{3} \mathrm{O}-\left(\mathrm{CH}_{2} \mathrm{CH}_{2} \mathrm{O}\right)_{5}-\mathrm{CH}_{3}$ & 266.38 \\
EO-8 & 8 & $\mathrm{CH}_{3} \mathrm{O}-\left(\mathrm{CH}_{2} \mathrm{CH}_{2} \mathrm{O}\right)_{8}-\mathrm{CH}_{3}$ & 398.56 \\
& & & \\
El-1 & 1 & $\mathrm{CH}_{3} \mathrm{NH}-\left(\mathrm{CH}_{2} \mathrm{CH}_{2} \mathrm{NH}\right)_{1}-\mathrm{CH}_{3}$ b & 88.18 \\
El-2 & 2 & $\mathrm{CH}_{3} \mathrm{NH}-\left(\mathrm{CH}_{2} \mathrm{CH}_{2} \mathrm{NH}\right)_{2}-\mathrm{CH}_{3}$ & 131.26 \\
El-3 & 3 & $\mathrm{CH}_{3} \mathrm{NH}-\left(\mathrm{CH}_{2} \mathrm{CH}_{2} \mathrm{NH}\right)_{3}-\mathrm{CH}_{3}$ & 174.34 \\
El-5 & 5 & $\mathrm{CH}_{3} \mathrm{NH}-\left(\mathrm{CH}_{2} \mathrm{CH}_{2} \mathrm{NH}\right)_{5}-\mathrm{CH}_{3}$ & 260.50 \\
El-8 & 8 & $\mathrm{CH}_{3} \mathrm{NH}-\left(\mathrm{CH}_{2} \mathrm{CH}_{2} \mathrm{NH}\right)_{8}-\mathrm{CH}_{3}$ & 389.74 \\
El-11 & 11 & $\mathrm{CH}_{3} \mathrm{NH}-\left(\mathrm{CH}_{2} \mathrm{CH}_{2} \mathrm{NH}\right)_{11}-\mathrm{CH}_{3}$ & 518.98 \\
\hline
\end{tabular}

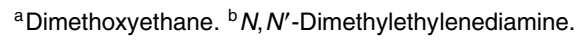

$$
\mathbf{C}^{\mathrm{n}=1} \mathbf{H}_{3}-\mathbf{O}^{2}-\left[\begin{array}{ccc}
\tau_{1} & \left.\mathbf{C}_{3} \mathbf{H}_{2}-\mathbf{C}^{4} \mathbf{H}_{2}-\mathbf{O}^{5}-\mathbf{C}^{6} \mathbf{H}_{2}-\mathbf{C}^{7} \mathbf{H}_{2}-\mathbf{O}^{8}\right]_{\mathbf{x} / 2}-\mathbf{C}^{3(\mathrm{x}+1)} \mathbf{H}_{3}
\end{array}\right.
$$

EO x-mer

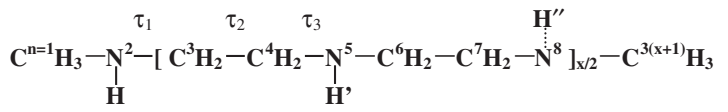

EI $x$-mer

Figure 1. Structural analyses for EO and El oligomer models, where $\mathrm{x}$ is the monomer unit number. The conformations were defined by $\left(\tau_{n} \tau_{n+1} \tau_{n+2}\right)_{x} \cdot \tau_{n}, \tau_{n+1}$, and $\tau_{n+2}$ are the dihedral angles for X-C, $\mathrm{C}-\mathrm{C}^{\prime}$, and $\mathrm{C}-\mathrm{X}^{\prime}\left(\mathrm{X}, \mathrm{X}^{\prime}: \mathrm{O}\right.$, or $\left.\mathrm{N}\right)$, respectively. For example, in EO1 , the $(\mathrm{ttt})_{1}$ conformation for $\left(\boldsymbol{\tau}_{1} \tau_{2} \tau_{3}\right)_{1}$ in the figure is all-trans. Pseudoasymmetry in El x-mer was defined by the following: $\mathrm{N}-\mathrm{H}$ and $\mathrm{N}-\mathrm{H}$ bonds in each of the $\mathrm{NH}$ groups in the figure are on this and that side of the paper, respectively, and for example, the pseudoasymmetry for the $\mathrm{N}^{2}-\mathrm{H}$ and the $\mathrm{N}^{5}-\mathrm{H}^{\prime}$ bonds is meso, and that for the $\mathrm{N}^{5}-\mathrm{H}^{\prime}$ and the $\mathrm{N}^{8}-\mathrm{H}^{\prime \prime}$ bonds is racemo. The lengths $(m / m, \AA / \AA)$ between non-bonding $N$ and $H$ in neighboring $\mathrm{NH}$ groups were analyzed as examples of the lengths of $\mathrm{N}^{5}-\mathrm{H}^{\prime \prime}$ / $\mathrm{H}^{\prime}-\mathrm{N}^{8}$ in the figure. The molecular length $(\mathrm{l}, \AA)$ was defined by the length between both terminal carbon atoms: $C^{1}-C^{3(x+1)}$.

functional theory (B3LYP) were used with the self consistent field (SCF) method. STO-3G, 3-21G, 6-31G, 6-31G(d) and $6-31+\mathrm{G}(\mathrm{d}, \mathrm{p})(\mathrm{d}, \mathrm{p}$ : polarization, + : diffuse function) were used as basis sets. The calculations were firstly carried out using STO-3G, and then with the higher level basis sets. The conformational energies (E: Hartree, 1 Hartree $=627.51 \mathrm{kcal} /$ mol, hereinafter referred to as energy) and some structural parameters (dihedral angles: $\tau_{\mathrm{n}}$, dipole moment: $\mu$, and others) were modified for the optimized structures (refer Figure 1). The conformations were specified based on the IUPAC rules ${ }^{23}$ as follows: $\tau_{\mathrm{n}}$ of trans $\left(\mathrm{t}^{ \pm}\right)$and gauche $\left(\mathrm{g}^{ \pm}\right)$are $\pm 120^{\circ}$ to $\pm 180^{\circ}$ and $\pm 0^{\circ}$ to $\pm 120^{\circ}$, respectively.

\section{Pseudoasymmetry in EI Oligomer Models}

PEI has pseudoasymmetry ${ }^{24}$ due to the conformation of neighboring imino groups (-NH-) and based on a nitrogen inversion (Figure 1). Therefore, for the conformational analysis of EI oligomers, it is necessary that the effects of pseudoasymmetry on the optimized structures are examined. The pseudoasymmetry in these calculations was controlled and determined in the structures of conformers optimized by some of the following designation systems: for the trans value in $\left(\tau_{\mathrm{n}} \tau_{\mathrm{n}+1} \tau_{\mathrm{n}+2}\right)_{\mathrm{x}}, \pi$ was used for the non-restriction system, and $-175^{\circ}$ or some combinations with $\pi$ and $-175^{\circ}$ were used for the restriction systems.

\section{RESULTS AND DISCUSSION}

\section{Energies of Conformers of EO Oligomers}

Considering that the structure of PEO crystals in the original state is a $7 / 2$ helix, ${ }^{1}$ the conformational analyses for oligomers were carried out until the 8-mer. The effect of calculation theory (RHF or B3LYP) on optimization was examined for the 8-mer. For B3LYP using higher level basis sets above 6-31G, 


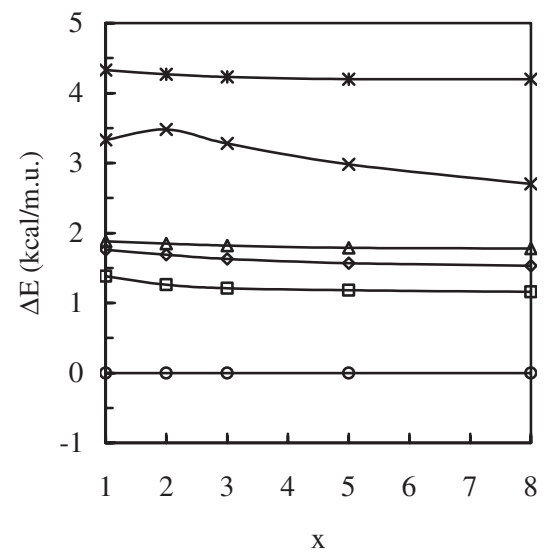

Figure 2. Plots of the energies $(\Delta E)$ of conformers optimized by RHF/6$31+G(d, p)$ against the monomer unit number $(x)$ in EO oligomers. $\bigcirc:(\mathrm{ttt})_{\mathrm{x}}, \square:\left(\operatorname{tg}^{+} \mathrm{t}\right)_{\mathrm{x}}, \diamond:\left(\operatorname{tg}^{+} \mathrm{g}^{-}\right)_{\mathrm{x}}, \triangle:\left(\mathrm{ttg}^{+}\right)_{\mathrm{x}}, \quad \mathrm{x}:\left(\operatorname{tg}^{+} \mathrm{g}^{+}\right)_{\mathrm{x}}$, $*$ : $\left(\mathrm{g}^{+} \mathrm{g}^{+} \mathrm{g}^{+}\right)_{\mathrm{x}}$. Each $\Delta \mathrm{E}$ was calculated based on the $\mathrm{E}$ value of the all-trans conformer: $(\mathrm{ttt})_{\mathrm{x}}$.

the calculations did not converge for all designated conformers, so that the RHF theory was adopted. No conformational rotations $(\mathrm{t} \leftrightarrow \mathrm{g})$ before and after optimizations, were found in any of the conformers. The energies calculated by RHF/ $6-31+\mathrm{G}(\mathrm{d}, \mathrm{p})$ are shown in Figure 2. The energies $(\Delta \mathrm{E}, \mathrm{kcal} /$ m.u.) of each conformer are the relative values per monomer unit, based on the $\mathrm{E}$ values of $(\mathrm{ttt})_{\mathrm{x}}$ conformers. As shown in Figure 2, the energy priorities for each conformer were constant and independent of the monomer unit number. $(\mathrm{ttt})_{\mathrm{x}}$ and $\left(\operatorname{tg}^{+} t\right)_{\mathrm{x}}$ were first and second stable $(\Delta \mathrm{E}=1.17-1.26 \mathrm{kcal} /$ m.u.), respectively. These energy priorities for both conformers were the same as the results of quantum chemical calculations reported by Smith et al. ${ }^{16}$ (for 1-mer) and Sasanuma et al. ${ }^{17}$ (for 1-, 3- and 5-mers). From an energetic aspect of the structural formation in a polymer crystal, it seems to be paradoxical that the most stable conformation until the 8-mer is not the same as the conformation observed for PEO crystals in the original state (tgt), ${ }^{1}$ however, it is the same as that observed in the stretched state $(\mathrm{ttt}){ }^{2}$ The actual structures of the EO oligomers and the energy priority of PEO crystals in both states are not known; therefore, the details of this paradox are not clear.
As shown in Figure 2, the $\Delta \mathrm{E}$ value of each conformer except for $\left(\operatorname{tg}^{+} \mathrm{g}^{+}\right)_{\mathrm{x}}$ seems to converge to a constant value above the 5-mer. The $\Delta \mathrm{E}$ value of $\left(\operatorname{tg}^{+} \mathrm{g}^{+}\right)_{\mathrm{x}}$ seems to consistently decrease above the 8 -mer. It would appear that the gauche effect on the energies of the $\left(\operatorname{tg}^{+} \mathrm{g}^{+}\right)_{\mathrm{X}}$ conformers is strongly influenced by the monomer unit number.

\section{Structures of Conformers of EO Oligomers}

The optimized structures of $(\mathrm{ttt})_{\mathrm{x}}$ and $\left(\operatorname{tg}^{+} \mathrm{t}\right)_{\mathrm{x}}$ as stable conformers for the 1 - to 8 -mers were examined. The results are shown in Table II. Dihedral angles and structural figures for the 8-mer are shown in Table III and Figure 3, respectively. XRD analysis results ${ }^{1,2}$ observed for PEO crystals are shown in Tables II and III for comparison. As shown in Table II, the structures of $(\mathrm{ttt})_{\mathrm{x}}$ agree with the structure observed for the PEO crystal in a stretched state (planar zigzag, fiber period: $7.12 \AA) .{ }^{2}$ The structure of $\left(\operatorname{tg}^{+} t\right)_{8}$ in the 8 -mer virtually agrees with that observed for a PEO crystal in the original state $(7 / 2$ helix, fiber period: $19.48 \AA) ;{ }^{1}$ however, the individual deviations ( $\mathrm{t}$ or $\mathrm{g}: \pm 0.2^{\circ}$ ) in the dihedral angles of $\left(\mathrm{tg}^{+} \mathrm{t}\right)_{8}$ are far different from those $\left(\mathrm{t}: \pm 6.8^{\circ}, \mathrm{g}: \pm 21.4^{\circ}\right)$ observed, as shown in Table III. These results suggest that the $7 / 2$ helix of PEO is "soft" and easily affected by intermolecular interactions. Regarding the interactions in PEO crystals, Kusanagi et al. ${ }^{25}$ have reported that the large strain in dihedral angles can be estimated as being due to the effects of intermolecular interactions, based on the results calculated by the minimization method for packing energy. The resulting difference between the dihedral angles calculated for a single chain model and those observed for an actual polymer supports this report.

\section{Energies of Conformers of EI Oligomers}

Considering that the structure of the linear PEI crystal is a $5 / 1$ helix, ${ }^{4}$ conformational analyses for oligomers until the 11 mer were carried out. The effect of calculation theory (RHF or B3LYP) on optimization was examined for the 11-mer. For B3LYP using higher level basis sets above 6-31G, the calculations did not converge for all designated conformers, so that RHF theory was adopted. The effect of pseudoasymmetry on the optimized structures was examined for $(\mathrm{ttt})_{\mathrm{x}}$

Table II. Structures of typical conformers optimized for EO oligomer models by RHF/6-31+G(d,p)

\begin{tabular}{|c|c|c|c|c|c|c|}
\hline No. & EO-1 & EO-2 & EO-3 & EO-5 & EO-8 & $(P E O)^{d}$ \\
\hline \multicolumn{7}{|l|}{ Conformers $(\mathrm{ttt})_{\mathrm{x}}$ : } \\
\hline Dihedral angles ${ }^{a}$ & $(\pi / \pi / \pi)_{1}$ & $(\pi / \pi / \pi)_{2}$ & $(\pi / \pi / \pi)_{3}$ & $(\pi / \pi / \pi)_{5}$ & $(\pi / \pi / \pi)_{8}$ & $(\mathrm{ttt})_{\mathrm{x}}$ \\
\hline Structures: & & & planar zigzag & planar zigzag & planar zigzag & planar zigzag \\
\hline Unit length $(2 \mathrm{~mol}, \AA$ ) & & & & 7.04 & 7.04 & 7.12 (F.P) \\
\hline$\mu(D)^{\mathrm{b}}: \mathrm{X} / \mathrm{Y} / \mathrm{Z}$ & $-0.0 / 0 /-0.0$ & $0.5 / 0 /-0.3$ & $-0.0 / 0 /-0.0$ & $-0.0 / 0 /-0.0$ & $-0.5 / 0 / 0.4$ & \\
\hline I: $C^{1}-C^{3(x+1)}(\AA)^{c}$ & 5.94 & 9.38 & 12.93 & 19.96 & 30.49 & \\
\hline \multicolumn{7}{|l|}{ Conformers $\left(\operatorname{tg}^{+} t\right)_{x}$ : } \\
\hline Dihedral angles & $\left(\mathrm{t}^{-} \mathrm{g}^{+} \mathrm{t}^{-}\right)_{1}$ & $\left(t^{-} g^{+} t^{-}\right)_{2}$ & $\left(t^{-} g^{+} t^{-}\right)_{3}$ & $\left(\mathrm{t}^{-} \mathrm{g}^{+} \mathrm{t}^{-}\right)_{5}$ & $\left(t^{-} g^{+} t^{-}\right)_{8}$ & $(\operatorname{tg} t)_{x}$ \\
\hline Structures: & & & helix & helix & helix $(7 / 2)$ & helix $(7 / 2)$ \\
\hline Unit length $(7 \mathrm{~mol}, \AA$ A $)$ & & & & & 19.53 & 19.48 (F.P.) \\
\hline$\mu(D): X / Y / Z$ & $0.5 / 0.4 / 0.1$ & $0.0 / 0.1 / 0.1$ & $0.3 /-0.1 /-0.3$ & $0.1 / 0.2 / 0.2$ & $-0.3 / 0.4 /-0.1$ & \\
\hline I: $C^{1}-C^{3(x+1)}(\AA)$ & 5.43 & 7.61 & 10.18 & 15.94 & 24.27 & \\
\hline
\end{tabular}

${ }^{\mathrm{a}}\left(\boldsymbol{\tau}_{\mathrm{n}} \boldsymbol{\tau}_{\mathrm{n}+1} \boldsymbol{\tau}_{\mathrm{n}+2}\right)_{\mathrm{x}}$. ${ }^{\mathrm{b}}$ Dipole moment, D: Debye. ${ }^{\mathrm{C}}$ Length between both terminal carbon atoms. ${ }^{\mathrm{d}}$ Results observed for PEO crystals by X-ray analyses. ${ }^{1,2}$ The (tgt) $\mathrm{x}$ and $(\mathrm{ttt})_{\mathrm{x}}$ conformations were observed in original ${ }^{1}$ and stretched states, ${ }^{2}$ respectively. 
Table III. Comparison between the dihedral angles of the $7 / 2$ helix calculated for EO-x and those observed for PEO

\begin{tabular}{|c|c|c|}
\hline & Calculated for $\mathrm{EO}-8^{\mathrm{a}}$ & Observed for $\mathrm{PEO}^{\mathrm{b}}$ \\
\hline \multicolumn{3}{|c|}{ Dihedral angles: $\left(\boldsymbol{\tau}_{\mathrm{n}} \boldsymbol{\tau}_{\mathrm{n}+1} \boldsymbol{\tau}_{\mathrm{n}+2}\right)_{\mathrm{x}}\left(^{\circ}\right)$} \\
\hline$\tau_{\mathrm{C} 1} / \tau_{\mathrm{O} 2} / \tau_{\mathrm{C} 3}$ & $-174.8 / 73.6 /-174.7$ & $181.7 / 79.1 / 190.5$ \\
\hline$\tau_{\mathrm{C} 4} / \tau_{\mathrm{O} 5} / \tau_{\mathrm{C} 6}$ & $-174.8 / 73.4 /-174.8$ & $182.0 / 60.2 / 180.3$ \\
\hline$\tau_{\mathrm{C} 7} / \tau_{\mathrm{O} 8} / \tau_{\mathrm{C} 9}$ & $-174.9 / 73.4 /-175.0$ & $186.2 / 91.8 / 193.9$ \\
\hline$\tau_{\mathrm{C} 10} / \tau_{\mathrm{O} 11} / \tau_{\mathrm{C} 12}$ & $-174.8 / 73.4 /-174.9$ & $180.3 / 49.0 / 182.8$ \\
\hline$\tau_{\mathrm{C} 13} / \tau_{\mathrm{O} 14} / \tau_{\mathrm{C} 15}$ & $-174.9 / 73.4 /-174.8$ & $204.3 / 74.2 / 174.1$ \\
\hline$\tau_{\mathrm{C} 16} / \tau_{\mathrm{O} 17} / \tau_{\mathrm{C} 18}$ & $-175.0 / 73.4 /-174.9$ & $182.9 / 67.8 / 188.8$ \\
\hline$\tau_{\mathrm{C} 19} / \tau_{\mathrm{O} 20} / \tau_{\mathrm{C} 21}$ & $-174.8 / 73.4 /-174.8$ & $193.8 / 57.2 / 182.2$ \\
\hline$\tau_{\mathrm{C} 22} / \tau_{\mathrm{O} 23} / \tau_{\mathrm{C} 24}$ & $-174.7 / 73.6 /-174.8$ & \\
\hline
\end{tabular}

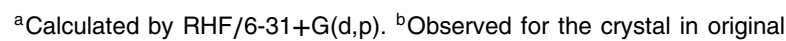
state by X-ray analysis. ${ }^{1}$

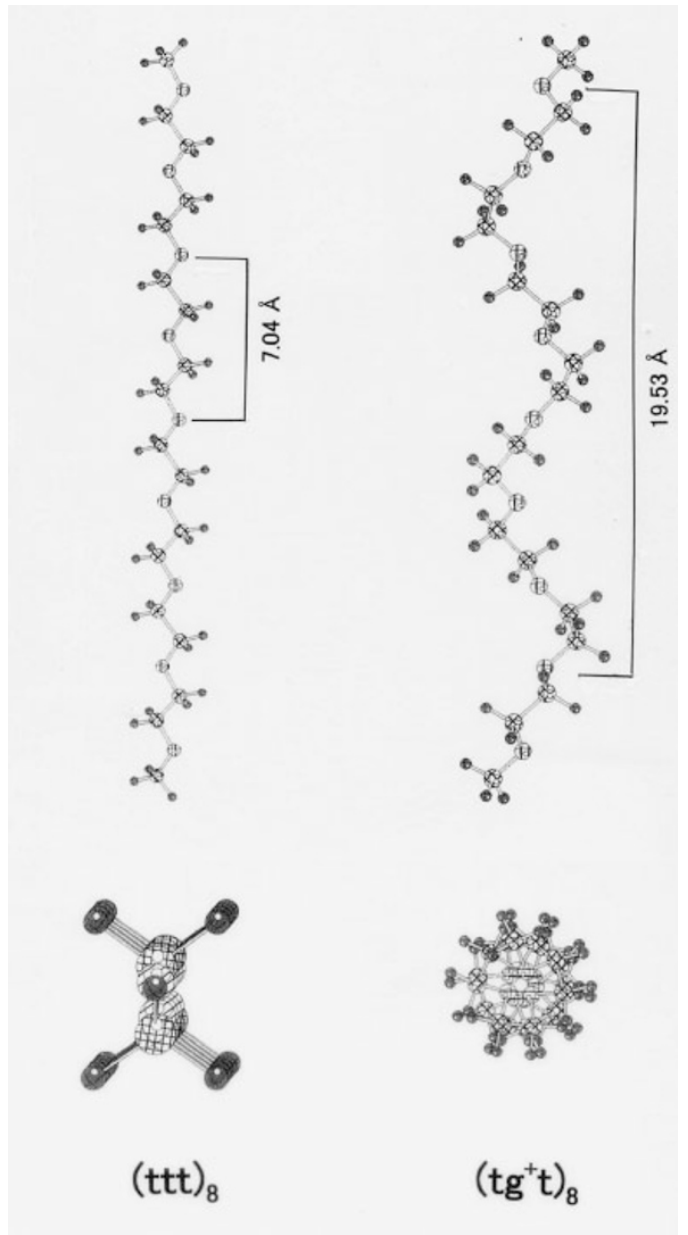

Figure 3. Structures of the conformers $\left((t t t)_{8}\right.$ and $\left.\left(\mathrm{tg}^{+} \mathrm{t}\right)_{8}\right)$ optimized for EO 8-mers by RHF/6-31+G(d,p). Upper and lower figures show the stereo oblique and chain axis projections, respectively.

conformers using the designation systems mentioned in the calculation section. The pseudoasymmetry and energies optimized by $\mathrm{RHF} / 6-31+\mathrm{G}(\mathrm{d}, \mathrm{p})$ are shown in Table IV. The pseudoasymmetry of $(\mathrm{ttt})_{\mathrm{x}}$ was racemo or syndiotactic in the "a" $\left((\pi / \pi / \pi)_{\mathrm{x}}\right.$ as non-restricted) and "b" $\left(\left(-175^{\circ} /-175^{\circ} / \pi\right)_{\mathrm{x}}\right.$ as partially restricted) systems, and was independent of the monomer unit number. For the "c" system $\left(\left(-175^{\circ} /-175^{\circ} /\right.\right.$ $\left.-175^{\circ}\right)_{\mathrm{x}}$ restricted), the pseudoasymmetry was meso or isotactic, and independent of the monomer unit number. The energies of $(\mathrm{ttt})_{\mathrm{x}}$ in the "a" system are extremely high, and those in the "b" and "c" systems are low and independent of the monomer unit number. These results indicate that the energies of $(\mathrm{ttt})_{\mathrm{x}}$ are strongly influenced by the dihedral angles of the main chain and not by the pseudoasymmetry. As shown in Table IV, the energy deviations in the "a" to "c" systems of $\left(\operatorname{tg}^{+} t\right)_{x}$ above the 3-mer were $0.57-1.14 \mathrm{kcal} / \mathrm{m}$.u., and those for other conformers, except $(\mathrm{ttt})_{\mathrm{x}}$ and $\left(\operatorname{tg}^{+} \mathrm{t}\right)_{\mathrm{x}}$, were not found. The restrictions of the dihedral angles in the $(\mathrm{ttt})_{\mathrm{x}}$ and $\left(\operatorname{tg}^{+} \mathrm{t}\right)_{\mathrm{x}}$ conformers contributed to the energy minimization for these conformers. Such effects were not found in the EO oligomers. These results suggest that the EI chain is "harder" than the EO chain, because of its strong intramolecular interactions.

The energy priorities for each conformer are shown in Figure 4, using the energies obtained for the " $b$ " system. The energy priorities for the 2- to 11-mers were constant and independent of the monomer unit number. $\left(\operatorname{tg}^{+} \mathrm{t}\right)_{\mathrm{x}}$ and $(\mathrm{ttt})_{\mathrm{x}}$ were first and second stable $(\Delta \mathrm{E}=1.32-1.42 \mathrm{kcal} / \mathrm{m} . \mathrm{u}$.), respectively; contrary to the priorities found for the EO oligomers. These results suggest that the gauche preference of $\mathrm{C}-\mathrm{C}$ bond in the EI chain is stronger than that in the EO chain, because of the effect of intramolecular interactions from the hydrogen bonds $(\mathrm{NH}-\mathrm{N})$ between neighboring imino groups in the EI chain. The energies of $\left(\operatorname{tg}^{+} t\right)_{\mathrm{x}}$ above the 2-mer are lowest, and support a conformation of (tgt) for the PEI crystal in the original state. ${ }^{4}$ Therefore, from an energetic aspect, it would be estimated that the main conformation of an actual linear EI oligomer is $(\operatorname{tgt})_{\mathrm{x}}$. As shown in Figure 4, only the $\Delta \mathrm{E}$ value of $\left(\operatorname{tg}^{+} \mathrm{t}\right)_{\mathrm{X}}$ for the 1-mer is extremely large, and its priority is different from that of the 2- to 11-mers. It may be considered that this result is due to the structural differences between the 1-mer and the 2- to 11-mers (see $\tau_{\mathrm{n}}$ and $\mathrm{m}$ in Table $\mathrm{V}$ mentioned later), but the detail is not clear. The energy of some conformers was influenced by the monomer unit number. As shown in Figure 4, the $\Delta E$ value of each conformer, except for $\left(\mathrm{g}^{+} \mathrm{g}^{+} \mathrm{g}^{+}\right)_{\mathrm{x}}$, seems to converge to a constant value above the 5-mer. The $\Delta \mathrm{E}$ value of $\left(\mathrm{g}^{+} \mathrm{g}^{+} \mathrm{g}^{+}\right)_{\mathrm{x}}$ seems to consistently decrease above the 8-mer. The $\left(\operatorname{tg}^{+} \mathrm{g}^{+}\right)_{\mathrm{x}}$ designated above the 2-mer changed to other conformations by optimization, as mentioned below. Taking into account these results, it would appear that the gauche effect on the energies of the $\left(\mathrm{g}^{+} \mathrm{g}^{+} \mathrm{g}^{+}\right)_{\mathrm{x}}$ and $\left(\mathrm{tg}^{+} \mathrm{g}^{+}\right)_{\mathrm{x}}$ conformers is strongly influenced by the monomer unit number.

The conformational rotations $(\mathrm{t} \leftrightarrow \mathrm{g})$ in the before and after optimizations were found for some conformers. As shown in Table IV, the $\left(\operatorname{tg}^{+} \mathrm{g}^{+}\right)_{\mathrm{x}}$ conformer designated for above the 2mer changed to $\left(\operatorname{tg}^{+} \mathrm{g}^{+}\right)\left(\mathrm{g}^{+} \mathrm{g}^{+} \mathrm{g}^{+}\right)_{\mathrm{x}-1}(\mathrm{t} \rightarrow \mathrm{g}$ rotation $)$, and the $\left(\mathrm{g}^{+} \mathrm{g}^{+} \mathrm{g}^{+}\right)_{\mathrm{x}}$ conformer designated for the 1-mer changed to $\left(\operatorname{tg}^{+} \mathrm{t}\right)_{1}(\mathrm{~g} \rightarrow \mathrm{t}$ rotation). This indicates that the populations of such designated conformations are extremely small, and the effects of intramolecular interactions on the conformation in the EI chain are specific compared with those in the EO chain.

\section{Optimized Structures of Conformers of EI Oligomers}

The structure of $\left(\operatorname{tg}^{+} t\right)_{\mathrm{x}}-\mathrm{b}$ ( " $\mathrm{b}$ " system) as the most stable conformer in the EI oligomers was examined first. The 
Table IV. Conformational analyses for El oligomer models by RHF/6-31+G(d,p), $(\Delta E, k c a l / m . u .)^{a}$

\begin{tabular}{|c|c|c|c|c|c|c|}
\hline No. & $\mathrm{El}-1$ & $\mathrm{El}-2$ & $\mathrm{El}-3$ & $\mathrm{El}-5$ & $\mathrm{El}-8$ & $\mathrm{El}-11$ \\
\hline \multicolumn{7}{|l|}{ Conformers optimized } \\
\hline$(\mathrm{ttt})_{\mathrm{x}}-\mathrm{a}$, racemo $(\mathrm{syn})^{\mathrm{c}}$ & 10.7 & 8.25 & 7.45 & 6.83 & 6.49 & 6.31 \\
\hline$(\mathrm{ttt})_{\mathrm{x}}-\mathrm{b}$, racemo $(\mathrm{syn})^{\mathrm{c}}$ & 0.06 & 0.07 & 0.04 & 0.06 & 0.08 & 0.07 \\
\hline$(\mathrm{ttt})_{\mathrm{x}}-\mathrm{c}$, meso (iso $)^{\mathrm{c}}$ & 0.00 & 0.00 & 0.00 & 0.00 & 0.00 & 0.00 \\
\hline$\left(\operatorname{tg}^{+} t\right)_{x}-a$ & 1.88 & -1.26 & -0.73 & -0.94 & -1.08 & -1.16 \\
\hline$\left(\operatorname{tg}^{+} t\right)_{x}-b$ & 1.88 & -1.26 & -1.30 & -1.29 & -1.33 & -1.35 \\
\hline$\left(\operatorname{tg}^{+} t\right)_{x}-\mathrm{C}$ & 1.88 & -1.26 & -0.73 & -0.15 & -0.48 & -0.67 \\
\hline$\left(\operatorname{tg}^{+} g^{+}\right)_{x-a}$ & -0.50 & 0.47 & 0.10 & $-^{d}$ & $-^{\mathrm{d}}$ & $-^{d}$ \\
\hline$\left(\operatorname{tg}^{+} g^{+}\right)_{x}-b$ & -0.50 & $-^{d}$ & $-^{d}$ & $-^{d}$ & $-^{d}$ & $-^{d}$ \\
\hline$\left(\operatorname{tgg}^{+}\right)_{x}-\mathrm{a}$ & 1.00 & 0.94 & 0.92 & 0.93 & 0.93 & 0.91 \\
\hline$\left(\mathrm{ttg}^{+}\right)_{x}-\mathrm{b}$ & 1.00 & 0.94 & 0.92 & 0.93 & 0.93 & 0.91 \\
\hline$\left(g^{+} g^{+} g^{+}\right)_{x}$ & $-^{e}$ & 2.26 & 2.01 & 1.66 & 1.45 & 1.33 \\
\hline$\left(\operatorname{tg}^{+} g^{-}\right)_{x}-a$ & 2.32 & 2.51 & 2.61 & 2.70 & 2.72 & 2.72 \\
\hline$\left(\operatorname{tg}^{+} g^{-}\right)_{x}-b$ & 2.32 & 2.51 & 2.61 & 2.70 & 2.72 & 2.72 \\
\hline
\end{tabular}

aCalculated based on the energy of $(\mathrm{ttt})_{\mathrm{x}}-\mathrm{c}$. ${ }^{\mathrm{b}}$ Some following designation systems for trans values were used in the optimizations: "a" (-a), "b" (-b), and "c" (-c) systems. ${ }^{c}$ Pseudoasymmetry (refer to Figure 1). ${ }^{d}$ Optimized from the designated $\left(\operatorname{tg}^{+} g^{+}\right)_{x}-a$ or $-b$ to $\left(\operatorname{tg}^{+} g^{+}\right)\left(g^{+} g^{+} g^{+}\right)_{x-1}$. ${ }^{e}$ Optimized from the designated $\left(g^{+} g^{+} g^{+}\right)_{x}$ to $\left(\operatorname{tg}^{+} t\right)_{x}$.

Table V. Structures of typical conformers optimized for El oligomer models by RHF/6-31+G(d,p)

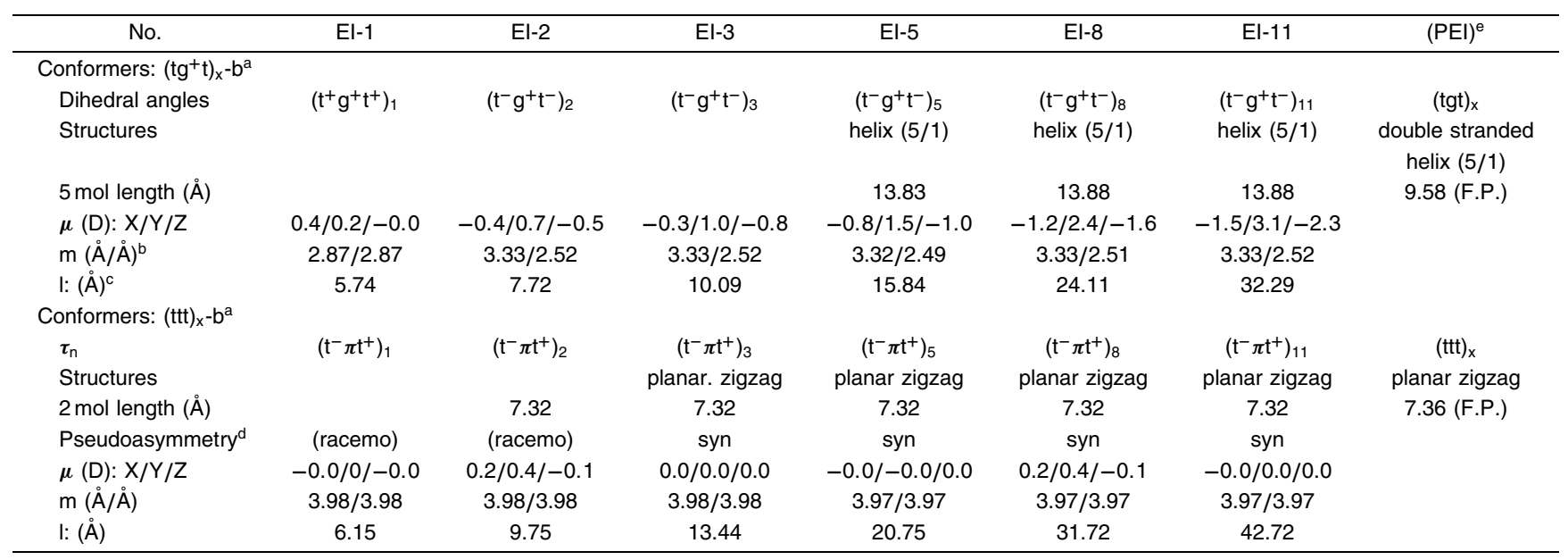

a Optimized for the "b" designation system. ${ }^{b}$ Lengths of $N-H^{\prime} N^{\prime} / H_{N}-N^{\prime}$ (refer to Figure 1). ${ }^{c}$ Length between both terminal carbons $C^{1}-C^{3(x+1)}$ (refer to Figure 1).

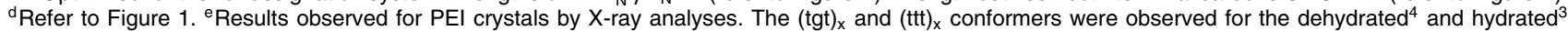
states, respectively.

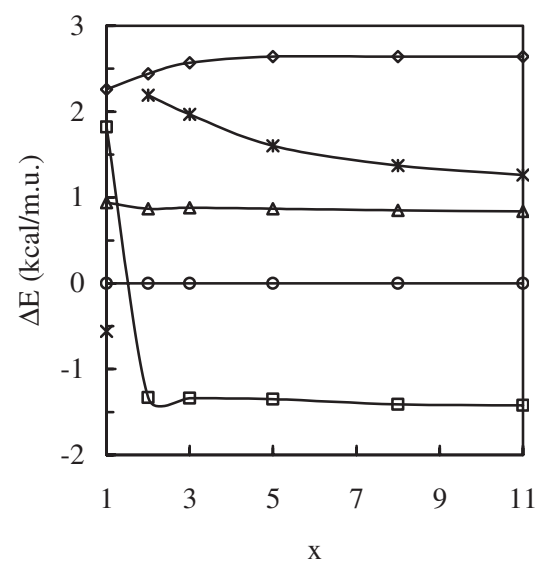

Figure 4. Plots of the energies $(\Delta \mathrm{E})$ of conformers optimized by RHF/6$31+\mathrm{G}(\mathrm{d}, \mathrm{p})$ against the monomer unit number $(\mathrm{x})$ in El oligomers. $\bigcirc:(\mathrm{ttt})_{\mathrm{x}}, \square:\left(\operatorname{tg}^{+} \mathrm{t}\right)_{\mathrm{x}}, \diamond:\left(\operatorname{tg}^{+} \mathrm{g}^{-}\right)_{\mathrm{x}}, \triangle:\left(\mathrm{ttg}^{+}\right)_{\mathrm{x}}, \quad \mathrm{x}:\left(\operatorname{tg}^{+} \mathrm{g}^{+}\right)_{\mathrm{x}}$, $*$ : $\left(\mathrm{g}^{+} \mathrm{g}^{+} \mathrm{g}^{+}\right)_{\mathrm{x}}$. Each $\Delta \mathrm{E}$ was calculated based on the $\mathrm{E}$ value of the all-trans conformer: $(\mathrm{ttt})_{\mathrm{x}}$. For the trans values used in designations, the "b" system $\left(\tau_{\mathrm{n}}, \boldsymbol{\tau}_{\mathrm{n}+1}:-175^{\circ}, \tau_{\mathrm{n}+2}: \pi\right)$ was used. structures of the 1- to 11-mers are shown in Table $\mathrm{V}$ with the results for PEI crystals (tgt helix) observed by XRD analysis. ${ }^{4}$ The dihedral angles $\left(\tau_{\mathrm{n}}\right)$ and structural figure of $\left(\mathrm{tg}^{+} \mathrm{t}\right)_{11}-\mathrm{b}$ for the 11-mer are shown in Table VI and Figure 5, respectively. The structures of $\left(\operatorname{tg}^{+} t\right)_{x}-b$ above the 5-mer are completely $5 / 1$ helical, as shown in Tables V and VI and Figure 5, and these results agree with those observed. However, the 5 mol lengths (13.83-13.88 ̊) calculated for these helices are far different from the observed fiber period $(9.58 \AA)$. It may be considered that this difference between the value calculated for a single chain and that observed for a double stranded helical chain results from the latter chain being shrunk along the screw axis by intermolecular interactions. For the intermolecular interaction of PEI crystal, Kusanagi ${ }^{26,27}$ has investigated using quantum chemical calculation under the periodic boundary condition, and mentioned that van der Waals force plays an important role in adition to hydrogen bond force in the stabilization of double stranded helical chain. 
Table VI. Structures of $\left(\operatorname{tg}^{+} t\right)_{11}$ conformers optimized for the El 11-mer by RHF/6-31+G(d,p)

\begin{tabular}{|c|c|c|c|}
\hline Conformers & $\left(\operatorname{tg}^{+} t\right)_{11-a}$ & $\left(\operatorname{tg}^{+} t\right)_{11}-b$ & $\left(\operatorname{tg}^{+} t\right)_{11-c}$ \\
\hline Designations for $\boldsymbol{\tau}_{\mathrm{n}}\left(^{\circ}\right)$ : & $(\pi / 60 / \pi)_{11}$ & $(-175 / 60 / \pi)_{11}$ & $(-175 / 60 /-175)_{11}$ \\
\hline \multicolumn{4}{|l|}{ Optimized structures: } \\
\hline$\Delta \mathrm{E}(\mathrm{kcal} / \mathrm{m} . \mathrm{u} .)^{\mathrm{a}}$ & 0.19 & 0.00 & 0.68 \\
\hline Structures: & inversed helical & helix $(5 / 1)$ & inversed and kinked helical \\
\hline 5 mol length $(\AA)$ & 13.76 & 13.88 & 12.61 \\
\hline Dihedral angles: $\boldsymbol{\tau}_{\mathrm{n}}\left({ }^{\circ}\right)$ & $\left(t / g^{+} / t\right)_{11}$ & $\left(t / g^{+} / t\right)_{11}$ & $\left(\mathrm{t} / \mathrm{g}^{+} / \mathrm{t}\right)_{11}$ \\
\hline$\tau_{\mathrm{C} 1} / \tau_{\mathrm{N} 2} / \tau_{\mathrm{C} 3}$ & $-174.4 / 64.5 /-173.0$ & $-173.0 / 64.5 /-173.5$ & $-176.1 / 62.9 / \underline{72.9}$ \\
\hline$\tau_{\mathrm{C} 4} / \tau_{\mathrm{N} 5} / \tau_{\mathrm{C} 6}$ & $-173.4 / 64.3 /-173.3$ & $-173.2 / 64.1 /-173.4$ & $-179.0 / 65.0 /-174.5$ \\
\hline$\tau_{\mathrm{C} 7} / \tau_{\mathrm{N} 8} / \tau_{\mathrm{C} 9}$ & $-173.5 / 64.2 /-173.3$ & $-173.2 / 64.1 /-173.2$ & $-173.7 / 64.9 /-173.0$ \\
\hline$\tau_{\mathrm{C} 10} / \tau_{\mathrm{N} 11} / \tau_{\mathrm{C} 12}$ & $-173.7 / 64.3 /-173.0$ & $-173.2 / 64.0 /-173.1$ & $-173.8 / 64.5 /-173.3$ \\
\hline$\tau_{\mathrm{C} 13} / \tau_{\mathrm{N} 14} / \tau_{\mathrm{C} 15}$ & $-173.8 / 65.0 /-175.0$ & $-173.3 / 64.0 /-173.1$ & $-173.9 / 65.0 /-175.1$ \\
\hline$\tau_{\mathrm{C} 16} / \tau_{\mathrm{N} 17} / \tau_{\mathrm{C} 18}$ & $\underline{168.9} / 57.9 / \underline{168.9}$ & $-173.3 / 64.0 /-173.1$ & $\underline{168.9} / 57.8 / 168.9$ \\
\hline$\tau_{\mathrm{C} 19} / \tau_{\mathrm{N} 20} / \tau_{\mathrm{C} 21}$ & $-175.0 / 65.0 /-173.8$ & $-173.3 / 64.0 /-173.1$ & $-175.1 / 65.0 /-173.9$ \\
\hline$\tau_{\mathrm{C} 22} / \tau_{\mathrm{N} 23} / \tau_{\mathrm{C} 24}$ & $-173.0 / 64.3 /-173.7$ & $-173.3 / 64.0 /-173.1$ & $-173.3 / 64.5 /-173.8$ \\
\hline$\tau_{\mathrm{C} 25} / \tau_{\mathrm{N} 26} / \tau_{\mathrm{C} 27}$ & $-173.3 / 64.2 /-173.4$ & $-173.3 / 64.0 /-173.1$ & $-173.0 / 64.9 /-173.7$ \\
\hline$\tau_{\mathrm{C} 28} / \tau_{\mathrm{N} 29} / \tau_{\mathrm{C} 30}$ & $-173.3 / 64.3 /-173.4$ & $-173.4 / 64.2 /-173.2$ & $-174.5 / 65.0 / \underline{179.0}$ \\
\hline$\tau_{\mathrm{C} 31} / \tau_{\mathrm{N} 32} / \tau_{\mathrm{C} 33}$ & $-173.0 / 64.5 /-174.4$ & $-173.0 / 64.5 /-174.3$ & $\underline{72.9} / 62.9 /-176.1$ \\
\hline$\mu(D): X / Y / Z$ & $0.1 / 0.0 /-0.0$ & $-1.5 / 3.1 / 0.0$ & $-0.2 / 0.4 /-0.5$ \\
\hline$m(\AA / \AA)^{b}$ & $3.33 / 2.51^{d}$ & $3.32 / 2.50$ & $3.33 / 2.53^{d}$ \\
\hline $\mathrm{I}:(\AA)^{\mathrm{c}}$ & 31.64 & 32.29 & 23.44 \\
\hline
\end{tabular}

${ }^{a}$ Calculated based on the energy of $\left(\operatorname{tg}^{+} t\right)_{11}-b .{ }^{b}$ m: Lengths of $N_{-} H^{\prime} N^{\prime} / H_{N}-N^{\prime}$ (refer to Figure 1). ${ }^{c}$ : Length between both terminal carbons: $C^{1}-C^{36}$. ${ }^{d} 2.66 /$ $2.66 \AA$ only in center segment.

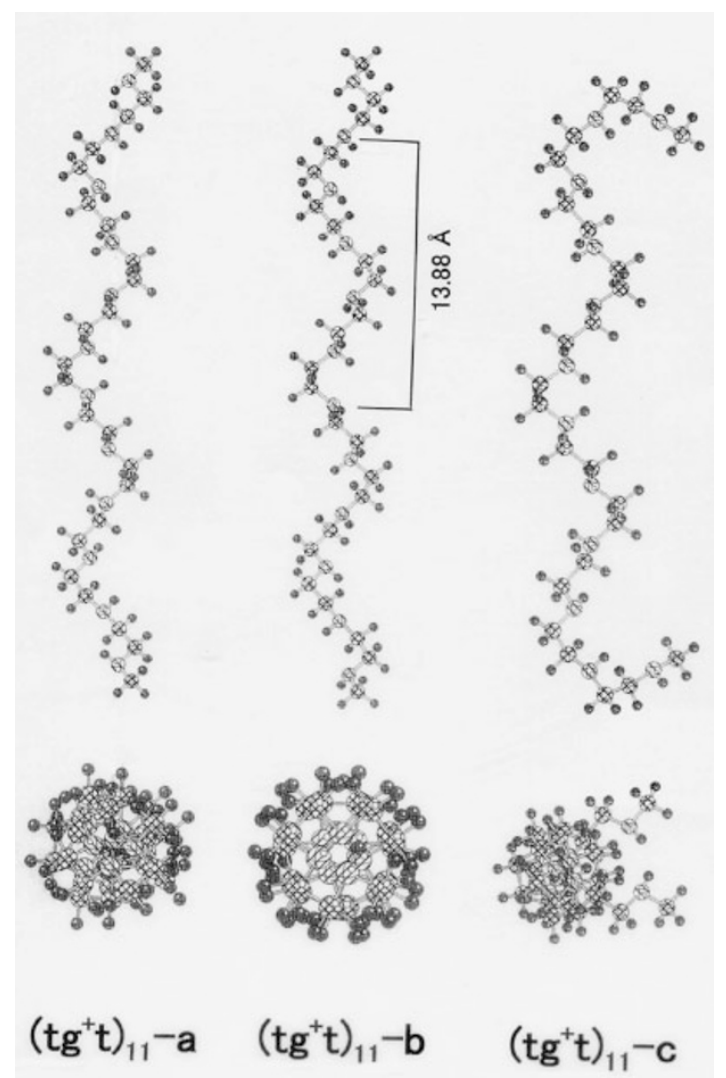

Figure 5. Some structures of $\left(\operatorname{tg}^{+} \mathrm{t}\right)_{11}$ conformers optimized for the El 11mer using some designation systems by $R H F / 6-31+G(d, p)$. $\left(\operatorname{tg}^{+} \mathrm{t}\right)_{11}$-a (reversed: $\mathrm{t}^{-} \rightarrow \mathrm{t}^{+}$in central), $\left(\mathrm{tg}^{+} \mathrm{t}\right)_{11}-\mathrm{b}(5 / 1$ helix) and $\left(\mathrm{tg}^{+} \mathrm{t}\right)_{11-\mathrm{c}}$ (reversed, and kinked: $\mathrm{t}^{-} \rightarrow \mathrm{g}^{+}$in terminals) were optimized using the "a", "b" and "c" designation systems, respectively (refer to Table $\mathrm{VI}$ ). Upper and lower figures show the stereo oblique and chain axis projections, respectively.
The structures of $\left(\operatorname{tg}^{+} t\right)_{x}-\mathrm{a}$ and $\left(\operatorname{tg}^{+} \mathrm{t}\right)_{\mathrm{x}}-\mathrm{c}$ as metastable conformers following $\left(\operatorname{tg}^{+} t\right)_{x}-b$ were examined. The structural results for the 11-mer show a skewed helix, as shown in Table VI and Figure 5. The structure of $\left(\operatorname{tg}^{+} \mathrm{t}\right)_{11^{-a}}$ is reversed $\left(\mathrm{t}^{-} \rightarrow \mathrm{t}^{+}\right.$in central), and that of $\left(\operatorname{tg}^{+} \mathrm{t}\right)_{11-\mathrm{c}}$ is reversed and kinked $\left(\mathrm{t}^{-} \rightarrow \mathrm{g}^{+}\right.$in terminals). The crystal structures of some actual oligomers are often different from those of the corresponding polymers, because of the low molecular weight characteristics, i.e. the low orientational characteristics in stretching. For example, the conformations observed for single crystals of the $3-$ mer $^{28}$ and $7-$ mer $^{29}$ of isotactic methylmethacrylate oligomers are skewed helices kinked in terminals, and are different from that of the polymer (all-trans helix). Taking into account these facts and the low energy differences between $\left(\operatorname{tg}^{+} \mathrm{t}\right)_{11-\mathrm{b}}$ and $\left(\operatorname{tg}^{+} \mathrm{t}\right)_{11-\mathrm{a}}$ or $\left(\operatorname{tg}^{+} \mathrm{t}\right)_{11-\mathrm{c}}(\Delta \mathrm{E}: 0.19$ in $-\mathrm{a}$, or 0.68 in -c, kcal/m.u.), the existence of such skewed helices in actual EI oligomers would be estimated.

The structures of $(\mathrm{ttt})_{\mathrm{x}}$ as second stable conformers were examined. The structures of $(\mathrm{ttt})_{\mathrm{x}}-\mathrm{b}$ for the 1- to 11-mers are shown in Table V, along with the XRD results observed for hydrated PEI crystals (ttt, planar zigzag). ${ }^{3}$ The calculated 2 mol lengths agree with the fiber period observed for hydrated PEI, as shown in Table V. This result means that an all-trans structure of a single chain is the same as that of the hydrated polymer. On the other hand, it has been made apparent by XRD and other analyses ${ }^{3-6}$ that dehydrated PEI crystals transform by hydration from a 5/1 double stranded helix to a planar zigzag. Considering these calculated and observed results, it may be estimated that only intramolecular interactions dominate in the structure of hydrated PEI and the intermolecular interactions in dehydrated structures are eliminated by hydration.

The distinctions between the structure calculated for a single chain and that experimentally observed for a polymer are effective in understanding the crystal structure and its trans- 
formation. In this study, conformational analyses in the gaseous phase were carried out for EO and EI oligomer models. Conformational analyses of these oligomers in solution are planned to take into account the hydrophilicity of these oligomers.

\section{CONCLUSION}

In order to compare the basic conformational characteristics of PEO and PEI, the conformational analyses for both oligomer models (single chain, 1- to 11-mers) have been done by quantum chemical calculation. The dependences of monomer unit number (above 2-mer) on the conformational energies of both oligomers were small, except for the $\left(\operatorname{tg}^{+} \mathrm{g}^{+}\right)_{\mathrm{x}}$ of EO and the $\left(\mathrm{g}^{+} \mathrm{g}^{+} \mathrm{g}^{+}\right)_{\mathrm{x}}$ of EI oligomers. The gauche preference of $\mathrm{C}-\mathrm{C}$ bond in the EI oligomer is stronger than that in the EO oligomer. It was estimated that this effect results in strong intramolecular interactions of hydrogen bonds (NH-N) in the EI chain. The structures of both oligomers having a tgt conformation agreed with those observed for PEO ( $7 / 2$ helix) and PEI (5/1 helix) crystals. However, the dihedral angles of the EO 8-mer and the 5 mol length of the EI 11-mer did not agree with the respective values observed for each polymer. The difference between the values calculated for the oligomer models (single chain) and those observed for the polymers was estimated to be due to the effect of intermolecular interactions in PEO or PEI. For EI oligomers having a tgt conformation, the existence of metastable skewed helical structures (reversed and/or kinked) were estimated in addition to the $5 / 1$ helix.

Received: September 17, 2007 Accepted: January 13, 2008 Published: March 4, 2008

\section{REFERENCES}

1. Y. Takahashi and H. Tadokoro, Macromolecules, 6, 672 (1973).

2. Y. Takahashi, I. Sumita, and H. Tadokoro, J. Polym. Sci., Polym.
Phys. Ed., 11, 2113 (1973).

3. Y. Chatani, H. Tadokoro, T. Saegusa, and H. Ikeda, Macromolecules, 14, 315 (1981).

4. Y. Chatani, T. Kobatake, H. Tadokoro, and R. Tanaka, Macromolecules, 15, 170 (1982).

5. Y. Chatani, T. Kobatake, and H. Tadokoro, Macromolecules, 16, 199 (1983).

6. T. Hashida, K. Tashiro, S. Aoshima, and Y. Inaki, Macromolecules, 35, 4330 (2002).

7. C. S. Harris, M. A. Ratner, and D. F. Shriver, Macromolecules, 20, 1778 (1987).

8. A. Akinc, D. M. Lynn, D. G. Anderson, and R. Langer, J. Am. Chem. Soc., 125, 5316 (2003).

9. J. E. Mark and P. J. Flory, J. Am. Chem. Soc., 87, 1415 (1965).

10. J. E. Mark and P. J. Flory, J. Am. Chem. Soc., 87, 3702 (1966).

11. G. Geun and J. Breitkreutz, Pharmazie, 49, 562 (1994).

12. H. Dong, J. K. Hyun, C. Durham, and R. A. Wheeler, Polymer, 42, 7809 (2001).

13. S. Wang, L. DeBolt, and J. E. Mark, Polym. Prepr., 34, 478 (1993).

14. S. Tsuzuki, T. Uchimaru, K. Tanabe, and T. Hirano, J. Phys. Chem., 97, 1346 (1993).

15. R. L. Jaffe, G. D. Smith, and D. Y. Yoon, J. Phys. Chem., 97, 12745 (1993).

16. G. D. Smith, D. Y. Yoon, and R. L. Jaffe, Macromolecules, 26, 5213 (1993).

17. Y. Sasanuma, H. Ohta, I. Touma, H. Matoba, Y. Hayashi, and A. Kaito, Macromolecules, 35, 3748 (2002).

18. Y. Sasanuma and K. Sugita, Polym. J., 38, 983 (2006).

19. S. E. Boesch, S. S. York, R. Frech, and R. A. Wheeler, Phys. Chem. Commun., 4, 1 (2001).

20. Y. Sasanuma, S. Hattori, S. Imazu, S. Ikeda, T. Kaizuka, T. Iijima, M. Sawanobori, M. A. Azam, R. V. Law, and J. H. G. Steinke, Macromolecules, 37, 9169 (2004).

21. M. Kobayashi and H. Sato, Kobunshi Ronbunshu, 64, 119 (2007).

22. "Gaussian 03 User's Reference," Gaussian Inc., Carnegie, PA, 2003.

23. J. Rigaudy and S. P. Klesney, "Nomenclature of Organic Chemistry," Section E, Pergamon Press, Oxford, 1979, p 483.

24. P. J. Flory, J. Am. Chem. Soc., 89, 1798 (1967).

25. H. Kusanagi and A. Ishimoto, Polym. Prepr. Jpn., 38, 3245 (1989).

26. H. Kusanagi, Polym. J., 25, 362 (1996).

27. H. Kusanagi, Polym. Prepr. Jpn., 53, 3610 (2004).

28. K. Ute, T. Nishimura, Y. Matsuura, and K. Hatada, Polym. J., 21, 231 (1989).

29. K. Ute, Y. Yamasaki, M. Naito, N. Miyatake, and K. Hatada, Polym. J., 27, 951 (1995). 